\title{
Reliability framework for power network assessment
}

\author{
Sambeet Mishra ${ }^{1}$, Chiara Bordin ${ }^{2}$, Jordi Mateo Fornes ${ }^{3}$, and Ivo Palu ${ }^{1}$ \\ ${ }^{1}$ Tallinn University of Technology, Estonia \\ ${ }^{2}$ SINTEF Energy research \\ ${ }^{3}$ Department of Computer Science, University of Lleida, Jaume II 69, 25001 Lleida, Spain.
}

\begin{abstract}
Reliability of power system in terms of investments in network maintenance and restructuring for power distribution network has gained importance due to increase in distributed generation. To determine the reliability of the power distribution network, the state of power apparatus, losses in the network and consumer satisfaction indices are key factors. Considering the aforementioned, this paper proposes a holistic reliability framework for power distribution networks. The framework lists the following factors: life cycle of power apparatus, environmental and sociological, node reliability, arc reliability. A case study for reliability evaluation is performed on a modified IEEE 14 bus network. Furthermore, multiple scenarios of generation fault or outage are studied and results are presented. The key contribution of this paper is to present a novel and holistic reliability framework to model distribution network.
\end{abstract}

\section{Introduction}

The aim of this paper is to develop an evaluation framework for reconfiguration of an electrical power system. Given study is influenced by the economical aspect of a network operator which implies to have the needed electrical, environmental, and economical indicators of an electrical power system to assess the optimal possibilities for reconstructing it. Many power system management utilities try to rationalize their network and optimize the total life-cycle costs of the components, due to the regulation of power quality and the reliability issues. For the given problem, many methods of assessment modeling have been introduced in the literature. System well-being method for power networks adequacy assessment using monte carlo simulation is presented, specifically for capacity reserve allocation [1]. This study expanded with renewable energy resources in [2]. This subject is further explored in the book series about reliable and sustainable power systems management [3]. Role of outage management and strategies are discussed here [4]. Reliability evaluation of power systems establishes measures to identify power interruptions and their implications [5]. However the approach is limited to power system events. For instance the state of the power apparatus is an important indicator to observe the system status. Detail concepts of power system reliability are presented in [6]. Reliability and connected parameters are introduced and and event tree analysis for event prediction is described here [7].

Many regionally owned utilities have been privatized, where the main concern are optimal investment planning for expansion and maintenance while maintaining the sys- tem reliability. Therefore, to improve and maintain power quality various regulation models have been introduced. These models enforce network companies to optimize their operations and schedule their maintenance activities without having to compromise the reliability nor the safety of the power system network. Reliability analysis is one of the key ways to inspect optimal asset management. A study has been conducted in [8-10] for evaluating the failure rates and reliability modeling for power distribution network. The reliability analysis has been utilized for optimal dis-connector allocation. In the analysis, the failure rates are constant for similar components, which are influenced by many different mechanical, environmental and electrical stresses. Usually for component failure models reliability calculations are based on the exponent distribution and failure rates are considered to be constant, which may be an inadequate approach. In some scenarios a scalar value is used for estimating the component failure rates while planning. Monte Carlo simulations are implemented to take into account effects of the surrounding, or enhanced component failure models which are based on constant component failure rates, to evaluate component related and the environmental aspects in reliability analysis. Another modeling approach is proportional hazard method, where age and other various additional information have been considered. Further information may include weather and environmental factors that affect the components. These models require significant data to be analyzed to investigate the essential dependencies affecting the component failure and malfunction. At the same time, Markov models are more commonly used, where the component failure rates are modeled by estimating the effects of the component faults for the system. Moreover, there are many factors that may lead to component failure 
such as weather condition and power surges. Therefore, predicting the component failure accurately is a challenge. As a consequence, the readiness of the power distribution network to optimally resolve the fault while ensuring uninterrupted power supply is the research objective.

\subsection{Motivation for Reliability-based Network Decision-making}

The main demand for reliability oriented network restructuring (RNR) is to have the estimates of failure rates which consider the main stress factors and the possibility to have first estimates from incomplete data to update values when more improved data is available. Components of distribution networks (DN) are modeled separately since the component failure rate is independent of factors that affect the power network. In this study, DN has been divided into four main components: overhead-lines (OHL), cables, transformers, and groups of switch-gear. For each component the main reasons for permanent faults and auto re-closings is determined. Separate failure rates for each component types are based on the reasons for a fault, e.g. aerial line overall failure rate is dependent on lightning, different weather conditions, and other fault related causes. The main stress factors that influence the failure rate, have been determined for all the reasons mentioned above. All the stress factors are classified into appropriate classes, for instance, the location could be by the seaside, near the forest or on a field. For all these classes a weight has been defined to represent the effects of a certain class to failure rate. For a total failure rate, temporary and permanent faults can be calculated. A practical approach on component modeling is to use the idea that parameters used in failure rate modeling should be possible to be affected by the selected planning strategies. Therefore, effects of the weather are included as an own parameter to failure rate modeling, however they are still included in condition information of the affect to the stress tolerance. Furthermore, the effects of component aging can be explained with other component related factors, therefore, life expectancy is included in condition weight information. Failure rate parameters must be determined before modeling methods can be used [11].

General failure rate of components were calculated as a weighted mean from failure rates of separate companies. Defined parameter groups are used to calculate the separate failure rates. Basic input data is the component information, i.e. component type, failure rate, and the network topology. Additionally, other information are needed regarding those factors that affect the analyses results, such as maintenance costs. In the enhanced radial reliability analysis, the network is with feeders and zones, which refer to a part of a feeder. In the given analysis, expected amount of permanent and temporary failures in a zone is calculated as an entirety of the individual network component failures. For a temporary fault, the whole feeder is experiencing the same short interruption. In the given analysis, experienced faults are defined for each load point. Determination of maintenance costs is done by analyzing the possible terrains where the components are located related to the total interruptions in the certain area. Therefore, the RNR framework can be expressed as an asset management model considering the Life-Cycle Assessment of power system components. To replace OHL's and underground cables, reliability of its reconfiguration is based on environmental and consumer preferences, $\mathrm{N}-1$ criteria, and the objectives for minimizing the investment costs. Reconfiguration of networks is primarily done to accommodate new consumers, which is achieved by extending the existing node through a new arc, and to replace some existing out-of-date lines. Network operators can adjust the failure rate and reliability parameters with their own network data. Smart grid components can identify the fault region of the feeder and update it with secure supply of energy from the same power network. Reliability indicators mainly include measures of outage duration and its frequency, the amount of power or energy not supplied, and the number of customers involved in outages. These indicators are determined over predefined period of time, such as SAIFI, SAIDI, CAIDI, ENS.

The rest of the paper is organized as the following sections: reliability framework, power network weight evaluation. In reliability framework each element of the framework concerning the power network is presented. An example case of IEEE 14-bus network is presented and discussed. Subsequently we evaluate generation loss scenarios and the results are presented in the power network evaluation section.

\section{Power System Reliability and Adequacy}

Power system adequacy refers to the condition of a power network considering generation, transmission and distribution units. Power system reliability refers to the state of network to sustain flow of energy from point of generation to demand at any point in time. The relationship between reliability and investment cost is presented in fig. 1. The figure signifies with outages or otherwise power interruptions the reliability reduces and the investment increases. Therefore, the planner need to pay attention so as to optimally plan for the expansions or maintenance of the distribution network. The indicators to determine the condition of power system can be broadly classified in to five categories: life cycle of power apparatus, environmental and sociological, node reliability, arc reliability and node reliability concerning losses. The table 1 outlines the associated indicators. These parameters organize the indicators taking into account the network as a node-arc formulation.

\subsection{Life cycle assessment (LCA)}

Life cycle assessment (LCA) is a method to determine the environmental impacts from a product, a process, or an activity. It is also used to assess the remaining utilization life. Throughout the product lifetime the impacts mainly originate from the power losses during the use phase, although installation, maintenance, and dismantling also contribute 


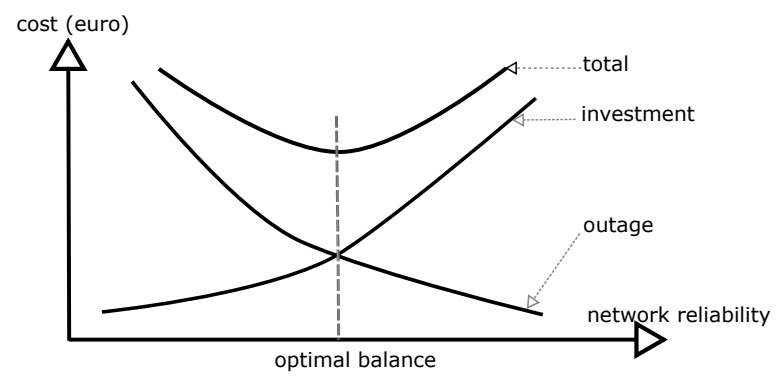

Figure 1: Relationship between reliability and cost

Table 1: Power system reliability and adequacy indicators

\begin{tabular}{|l|l|l|}
\hline LCA & $\begin{array}{l}\text { Environmental } \\
\text { \& Sociological }\end{array}$ & $\begin{array}{l}\text { Node reliability } \\
\text { indicators }\end{array}$ \\
\hline Cable & Terrain & SAIFI \\
value \\
OHL & Weather & SAIDI \\
value \\
Transformer & $\begin{array}{l}\text { Consumption } \\
\text { Switchgear }\end{array}$ & Generation \\
Emissions & Availability \\
\hline Arc reliability & $\begin{array}{l}\text { Node reliability } \\
\text { indicators }\end{array}$ & \\
\hline AIT & LOLE & \\
AIF & LOEE & \\
AID & EIR & \\
\hline
\end{tabular}

to it. Transmission and distribution assets have been comprised of power lines, cables, transformers, substations, and other electrical components to generate wide range of environmental impacts, such as the equipment emissions and material weight value. The life cycle stages viewed are interpreted as the production or the manufacturing phase of a product or its use phase. The used life cycle inventory consists of material requirement for grid components and their environmental impact. For all the components, the functional unit is one equipment operational during the lifetime.

Given network is a high and medium voltage network, with three distributed generation inputs. Biomass and oil shale produce the distributed generated energy, with an additional input from a submarine cable. The network nodes are depicted as substations with each bus-line having an ideal energy consumer as residential or commercial. The transmission line is either an underground cable or an overhead-line. The normalized weights are allocated to arcs and nodes based on the historical data and expert's opinion. For instance, an indicator depicting transmission line weight is valued at $4000.5 \mathrm{~kg} / \mathrm{km}$, although Switchgear emissions are valued at $185.38 \mathrm{~kg} \mathrm{CO}_{2}$ per transformer. Weights are normalized and translated to the cost of maintenance for the distribution system operator. In this method, dissimilar components can be compared based on the cost of investment.

\subsubsection{Cable}

Medium voltage power cables are characterized in [12]. In this study we concentrate on three different voltage levels, with each having one or two different types of cables, therefore five different cables are evaluated. Cables are chosen based on their suitable voltage level, cable diameter and the conductor and the insulation type.

A transmission line of 6 or $10 \mathrm{kV}$ spanning over $9 \mathrm{~km}$, a three-core cable is proposed with diameter of $3 * 70 \mathrm{~mm}^{2}$. This cable weighs $5400 \mathrm{~kg} / \mathrm{km}$. Cable indicators in a network reconstruction evaluation are the conductor and insulation. In the example, conductor weight is calculated as the diameter of the conductor (i.e. Al conductor diameter $=9.8 \mathrm{~mm}$ ) multiplied with conduction material density $(\mathrm{Al}$ density $=2.7 \mathrm{~kg} / \mathrm{km})$. i.e. Cable, which weighs 5400 $\mathrm{kg} / \mathrm{km}$ has an aluminum conductor which weighs 124.7 $\mathrm{kg} / \mathrm{km}$ and insulation of $5275.3 \mathrm{~kg} / \mathrm{km}$ [13]. Different kinds of lines vary mainly in sizing of the cross section of the conductor, however the mentioned cross section is not the actual measurement of the wire, but rather the area of the conductor gives the needed cross section, such as aluminum, copper or steel. Data from cable producers is used to identify the correct amount of material input for each of the line types. For the power system network, at three different voltage levels, each voltage level is applied with power lines with the following conductors: aluminum (2.7 $\left.\frac{\mathrm{gm}}{\mathrm{cm}^{3}}\right)$, copper $\left(8.89 \frac{\mathrm{gm}}{\mathrm{cm}^{3}}\right)$ and steel $\left(7.83 \frac{\mathrm{gm}}{\mathrm{cm}^{3}}\right)$. The power line data is derived from manufacturer's data provided by ABB [14]. From the catalogue, the most suitable power lines are chosen, based on their voltage level and the conductor material. Considering the length of a given power line and the cross section provided by $\mathrm{ABB}$, it is possible to find the weight of a conductor [14].

Given the total length of underground cables and overhead lines, and additionally it contains the calculated values of the power line conductor and insulation weight relative to their material. The insulation material composition is also derived from the manufacturer specifications [14]. Typically, the installation of cables requires extensive underground pathways. Due to insufficient data, these parameters are not included. However, some general construction processes are included, such as the weight difference and the relation to the actual line weight are applied. These electrical masts are calculated by their tension and sag related the length between each pole. Also, different height of masts is assumed for each voltage level. Poles are described by their suitable voltage level, material use, height, span, tension, and sag.

Table 2: Reliability assessment of power conductor

\begin{tabular}{|lll|}
\hline $\begin{array}{l}\text { Voltage level } \\
(\mathbf{k V})\end{array}$ & $\begin{array}{l}\text { Cable length } \\
(\mathbf{k m})\end{array}$ & $\begin{array}{l}\text { Cable diameter } \\
\left(\mathrm{mm}^{2}\right)\end{array}$ \\
\hline $6+10$ & 9 & $3 * 70$ \\
$\begin{array}{l}\text { Cable line } \\
\text { weight }(\mathbf{k g} / \mathbf{k m})\end{array}$ & $\begin{array}{l}\text { Conductor } \\
\text { diameter }(\mathbf{m m})\end{array}$ & $\begin{array}{l}\text { Weight } \\
(\mathbf{k g} / \mathbf{k m})\end{array}$ \\
\hline 5400 & 9.8 & $\begin{array}{l}646.5 \\
\text { Weight }\end{array}$ \\
Conductor material & & \\
& Insulation type & \\
$($ Aluminum $(\mathrm{Al}))$ & & $(\mathbf{k g} / \mathbf{k m})$ \\
\hline $\mathrm{Al}$ & $\mathrm{XLPE}$ & 5275.3 \\
\hline
\end{tabular}

\subsubsection{Transformer and switch-gear}

Transformers used in this study are assumed to be ideal, without having to relate to the criterion $\mathrm{N}-1$ (in case one 


\begin{tabular}{|c|c|c|c|c|c|c|c|}
\hline Node & 1 & 2 & 3 & 4 & 5 & 6 & 7 \\
\hline $\begin{array}{l}\text { Voltage level } \\
(\mathbf{k V})\end{array}$ & $110 / 10$ & $110 / 35 / 10 / 6$ & $110 / 35 / 6$ & $110 / 35 / 6$ & $110 / 10$ & $35 / 6$ & $110 / 35 / 6$ \\
\hline Generation [0/1] & 0 & 1 & 0 & 0 & 0 & 0 & 1 \\
\hline Generation, kWh & 0 & 925 & 0 & 0 & 0 & 0 & 1000 \\
\hline $\begin{array}{l}\text { Transformer } \\
{[\mathbf{0 , 1 , 2 ]}}\end{array}$ & 1 & 2 & 1 & 1 & 1 & 1 & 1 \\
\hline $\begin{array}{l}\text { Transformer } \\
\text { type }[1,2,3]\end{array}$ & 1 & $1+3$ & 2 & 2 & 1 & 3 & 2 \\
\hline Life expectancy & 0.2 & 0.2 & 0.2 & 0.2 & 0.2 & 0.2 & 0.2 \\
\hline $\begin{array}{l}\text { Conductor weight } \\
\text { ( kg/Trfo) }\end{array}$ & 0.61 & 1.00 & 0.57 & 0.57 & 0.61 & 0.00 & 0.57 \\
\hline $\begin{array}{l}\text { Conductor weight } \\
(\mathrm{kg} / \mathrm{kVA})\end{array}$ & 1.00 & 1.00 & 0.001 & 0.001 & 1.00 & 0.00 & 0.001 \\
\hline $\begin{array}{l}\text { Trfo_oil weight } \\
\text { (kg/Trfo) }\end{array}$ & 0.56 & 1.00 & 0.22 & 0.22 & 0.56 & 0.00 & 0.22 \\
\hline $\begin{array}{l}\text { Trfo_oil weight } \\
\text { (kg/kVA) }\end{array}$ & 1.00 & 1.00 & 0.00 & 0.00 & 1.00 & 0.0002 & 0.00 \\
\hline $\begin{array}{l}\text { Energy demand } \\
(\mathrm{kWh})\end{array}$ & 250 & 275 & 275 & 325 & 300 & 350 & 350 \\
\hline Energy demand & 0.00 & 0.25 & 0.25 & 0.75 & 0.50 & 1.00 & 1.00 \\
\hline SG type & 1 & 4 & 2 & 2 & 1 & 3 & 2 \\
\hline Life expectancy & 0 & 0 & 0 & 0 & 0 & 0 & 0 \\
\hline GWP & 0.14 & 1.00 & 0.02 & 0.02 & 0.14 & 0.00 & 0.02 \\
\hline $\mathbf{A P}$ & 0.22 & 1.00 & 0.03 & 0.03 & 0.22 & 0.00 & 0.03 \\
\hline NP & 0.44 & 1.00 & 0.05 & 0.05 & 0.44 & 0.00 & 0.05 \\
\hline $\begin{array}{l}\text { SF6 (\% of all } \\
\text { emissions ) }\end{array}$ & 0.00 & 1.00 & 0.11 & 0.11 & 0.00 & 0.02 & 0.11 \\
\hline Total value: & 0.15 & 1.00 & 0.05 & 0.05 & 0.15 & 0.01 & 0.05 \\
\hline Terrain & 4.00 & 9.00 & 5.00 & 7.00 & 4.00 & 5.00 & 7.00 \\
\hline Terrain coefficients & 0.38 & 1.00 & 0.50 & 0.75 & 0.38 & 0.50 & 0.75 \\
\hline
\end{tabular}

Table 3: Reliability indicators and weights for modified IEEE 14 bus network [1/2]

transformer is interrupted, the power flow will continue). Therefore, a substation is only constructed with 1 transformer, with one exception of a substation with four different voltages. For that substation, the assumption of having two transformers gives a more effective distribution. The data for this table is provide by ABB [14]. Transformer weight is based on the conductor material (copper) weight in the wiring and the profile during the manufacturing phase. Furthermore, the transformers under evaluation are assumed to be almost equal to the ones from the manufacturer, e.g. for a $110 / 10 \mathrm{kV}$ substation, 220/15.6 $\mathrm{kV}$ transformer is used [110-220]. For a network substation, the different combinations of switch-gear are assumed based on their operating voltage level. These combinations are needed for environmental impact assessment, which will be talked about later on. Switch-gear values are based on the environmental impact per transformer.

\subsection{Node reliability indicators}

Given reliability indicators combine the factors related to outage duration or the response time, frequency of outage, number of customers involved in interruption or their lost power and energy. System average interruption frequency index (SAIFI), system average interruption duration index (SAIDI), energy not supplied (ENS), average service availability index (Availability), average interruption time (AIT), average interruption frequency (AIF), average interruption duration (AID) are among the measures to evaluate the interruptions and its impacts.

\subsubsection{Terrain and weather effects}

The failure rate of any component in a power system network is assumed to be influenced by different internal (quality and type of transmission line) and external factors (terrain, topology and weather conditions). Nine different terrain types are considered for this study that outlines the network environments. For example, the hill-like location has a lower failure rate compared to a commercial location, because in the commercial surrounding, there are more internal factors related to the consumption, and seaside has a lower failure rate than the forest, because forest is prone to fail e.g, trees falling. For the outage of a generation unit a maintenance cost incurs for the system operator. Factors like replacement or repair or maintenance cost for a corridor or line segment of the power network is considered. Additionally the environmental impact of an outage in terms of fuel consumption during the servicing and resulting environmental impact is also taken into consideration [15].

\section{Evaluation of Power Network Condition under Outages}

The fig. 2 presents the IEEE-14 bus network with zones. Each zone presents a geographical location. Tables 3 and 4 presents the indicators and the corresponding values (normalized) for measuring the system reliability based on nodes under the proposed framework.

The formulation for probability of failure $\Omega_{n}$ for bus $n$ can be presented as in (1). In (2) frequency of failure $\Omega_{n}^{f}$ is presented [6].

$$
\begin{array}{r}
\Omega_{n}=\sum_{i}\left[P\left(O_{j}\right)\left(P_{i, g} P_{l, i}-P_{g, i} P_{l, i}\right)\right] \\
\Omega_{n}^{f}=\sum_{i}\left[O_{j}^{f}\left(P_{i, g} P_{l, i}-P_{g, i} P_{l, i}\right)\right]
\end{array}
$$




\begin{tabular}{|c|c|c|c|c|c|c|c|}
\hline Nodes & 8 & 9 & 10 & 11 & 12 & 13 & 14 \\
\hline Voltage level (kV) & $110 / 35 / 6$ & $110 / 10 / 6$ & $110 / 35 / 10$ & $110 / 10$ & $110 / 10$ & $110 / 35 / 6$ & $35 / 6$ \\
\hline Generation [0/1] & 0.00 & 0.00 & 1.00 & 1.00 & 0.00 & 0.00 & 0.00 \\
\hline Generation, kWh & 0.00 & 0.00 & 2000.00 & 1000.00 & 0.00 & 0.00 & 0.00 \\
\hline $\begin{array}{l}\text { Transformer } \\
{[0,1,2]}\end{array}$ & 1.00 & 1.00 & 2.00 & 1.00 & 1.00 & 1.00 & 1.00 \\
\hline $\begin{array}{l}\text { Transformer } \\
\text { type }[1,2,3]\end{array}$ & 2.00 & 2.00 & $1+3$ & 1.00 & 1.00 & 2.00 & 3.00 \\
\hline Life expectancy & 0.20 & 0.20 & 0.20 & 0.20 & 0.20 & 0.20 & 0.20 \\
\hline $\begin{array}{l}\text { Conductor weight } \\
\text { ( kg/Trfo) }\end{array}$ & 0.57 & 0.57 & 1.00 & 0.61 & 0.61 & 0.57 & 0.00 \\
\hline $\begin{array}{l}\text { Conductor weight } \\
(\mathrm{kg} / \mathrm{kVA})\end{array}$ & 0.00 & 0.00 & 1.00 & 1.00 & 1.00 & 0.00 & 0.00 \\
\hline $\begin{array}{l}\text { Trfo_oil weight } \\
\text { (kg/Trfo) }\end{array}$ & 0.22 & 0.22 & 1.00 & 0.56 & 0.56 & 0.22 & 0.00 \\
\hline $\begin{array}{l}\text { Trfo_oil weight } \\
(\mathrm{kg} / \mathbf{k V A})\end{array}$ & 0.00 & 0.00 & 1.00 & 1.00 & 1.00 & 0.00 & 0.00 \\
\hline $\begin{array}{l}\text { Energy demand } \\
(\mathbf{k W h})\end{array}$ & 325.00 & 350.00 & 275.00 & 300.00 & 300.00 & 325.00 & 300.00 \\
\hline Energy demand & 0.75 & 1.00 & 0.25 & 0.50 & 0.50 & 0.75 & 0.50 \\
\hline $\begin{array}{l}\text { Switch-gear } \\
\text { type }\end{array}$ & 2.00 & 2.00 & 4.00 & 1.00 & 1.00 & 2.00 & 3.00 \\
\hline Life expectancy & 0.00 & 0.00 & 0.00 & 0.00 & 0.00 & 0.00 & 0.00 \\
\hline GWP & 0.02 & 0.02 & 1.00 & 0.14 & 0.14 & 0.02 & 0.00 \\
\hline AP & 0.03 & 0.03 & 1.00 & 0.22 & 0.22 & 0.03 & 0.00 \\
\hline NP & 0.05 & 0.05 & 1.00 & 0.44 & 0.44 & 0.05 & 0.00 \\
\hline $\begin{array}{l}\text { SF6 ( } \% \text { of all } \\
\text { emissions ) }\end{array}$ & 0.11 & 0.11 & 1.00 & 0.00 & 0.00 & 0.11 & 0.02 \\
\hline Total value: & 0.05 & 0.05 & 1.00 & 0.15 & 0.15 & 0.05 & 0.01 \\
\hline Terrain & 7.00 & 5.00 & 9.00 & 5.00 & 1.00 & 4.00 & 5.00 \\
\hline Terrain coefficients & 0.75 & 0.50 & 1.00 & 0.50 & 1.00 & 0.38 & 0.50 \\
\hline
\end{tabular}

Table 4: Reliability indicators and values for modified IEEE 14 bus network [2/2]

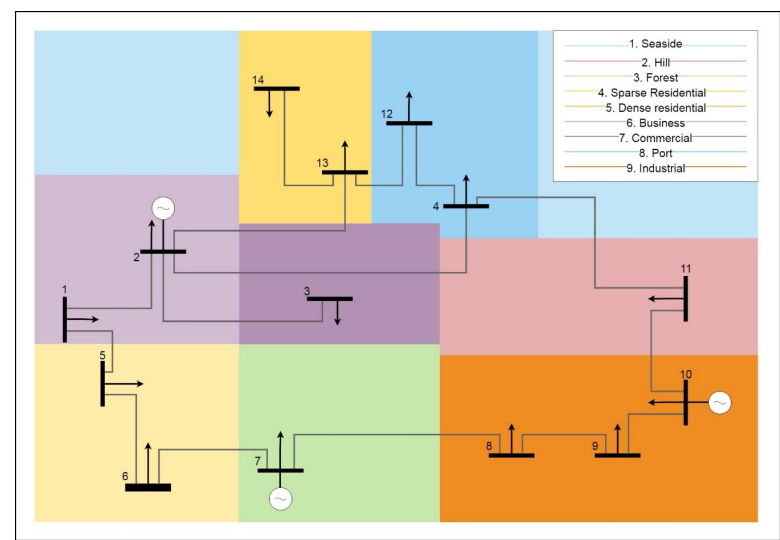

Figure 2: Classification of modified IEEE-14 bus network into zones based on weights

Where $O_{j}$ is the condition of outage in the power transmission network. $P_{i, q}$ is the probability of occurrence of capacity outage beyond reserves. And probability of uninterrupted power supply. The availability $(\gamma)$ is calculated as $\gamma=1-\frac{60 * E N S}{\sum_{i} P_{i}}$ where $P_{i}$ is average power supplied by the total system and ENS (Energy not supplied because of interruption) and $P_{i}$ stands for power interruption for incident $i$. The total cost is product of component capital cost times availability. And the repair cost is the cost of repair times the total cost. Similarly the maintenance cost is value of fault times the repair costs.

Considering the four generation units 15 generation outage states are assessed. Figure 3 demonstrates the network topology and number of consumers with respective per unit energy consumption. There are 314 numbers of consumers in the 14 bus network with total consumption

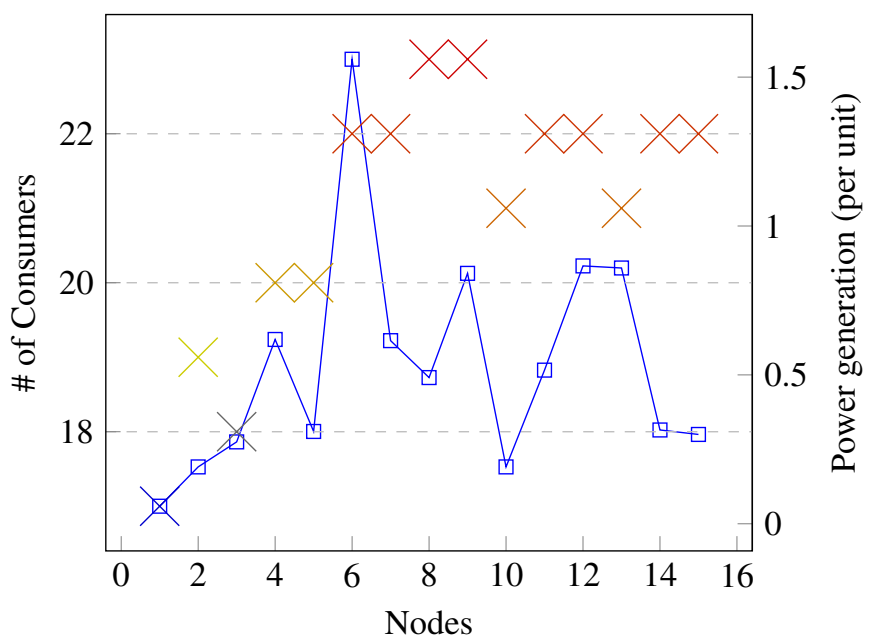

Figure 3: Node wise number of consumers with respective consumption in per unit

of 8.008. Table 5 states the power system indicators for evaluating the faults and losses with respect to line for interrupted load. The sum total SAIFI, SAIDI, ENS for the network are $0.00426,8.925$ and 0.196 respectively. The relative cost in $€$ for investment, repair and maintenance are presented in table 6 . The net overall investment is 29.29215 followed by 0.124837 for repair and 0.0005320 for maintenance cost. 


\begin{tabular}{|c|ccccccc|}
\hline Line & Interrupted load & SAIFI & SAIDI & ENS & Availability & CAIDI & CAIFI \\
\hline 1 & 0.0002514 & 0.000231 & 0.48 & 0.001442673 & 0.999999849 & 0.226468312 & 0.000230734 \\
2 & 0.0008140 & 0.000258 & 0.54 & 0.004670347 & 0.999999831 & 0.253111642 & 0.000257879 \\
3 & 0.0011720 & 0.000244 & 0.51 & 0.006724321 & 0.99999984 & 0.239789977 & 0.000244307 \\
4 & 0.0026381 & 0.000271 & 0.57 & 0.015135836 & 0.999999822 & 0.266433308 & 0.000271452 \\
5 & 0.0013212 & 0.000271 & 0.57 & 0.007580144 & 0.999999822 & 0.266433308 & 0.000271452 \\
6 & 0.0066484 & 0.000299 & 0.63 & 0.038145242 & 0.999999804 & 0.293076639 & 0.000298597 \\
7 & 0.0026210 & 0.000299 & 0.63 & 0.015038028 & 0.999999804 & 0.293076639 & 0.000298597 \\
8 & 0.0020925 & 0.000312 & 0.65 & 0.012005970 & 0.999999796 & 0.306398304 & 0.00031217 \\
9 & 0.0035842 & 0.000312 & 0.65 & 0.020564198 & 0.999999796 & 0.306398304 & 0.00031217 \\
10 & 0.0008140 & 0.000285 & 0.60 & 0.004670347 & 0.999999813 & 0.279754973 & 0.000285025 \\
11 & 0.0021991 & 0.000299 & 0.63 & 0.012617272 & 0.999999804 & 0.293076639 & 0.000298597 \\
12 & 0.0036907 & 0.000299 & 0.63 & 0.021175500 & 0.999999804 & 0.293076639 & 0.000298597 \\
13 & 0.0036609 & 0.000285 & 0.60 & 0.021004335 & 0.999999813 & 0.279754973 & 0.000285025 \\
14 & 0.0013425 & 0.000299 & 0.63 & 0.007702405 & 0.999999804 & 0.293076639 & 0.000298597 \\
15 & 0.0012785 & 0.000299 & 0.63 & 0.007335623 & 0.999999804 & 0.293076639 & 0.000298597 \\
\hline
\end{tabular}

Table 5: indicators regarding system interruptions and losses $10^{-3}$

\begin{tabular}{|c|ccc|ccc|}
\hline \multirow{2}{*}{ Line } & \multicolumn{3}{|c|}{ Loss } & \multicolumn{3}{c|}{ Cost } \\
\cline { 2 - 7 } & LOLE & LOEE & EIR & Investment & Repair & Maintenance \\
\hline 1 & 0.001051799 & $1.85256 \mathrm{E}-06$ & 0.999998147 & 3.49999 & 0.014916260 & 0.000063570 \\
2 & 0.003404977 & $1.94149 \mathrm{E}-05$ & 0.999980585 & 3.49993 & 0.014915998 & 0.000063569 \\
3 & 0.004902454 & $4.0247 \mathrm{E}-05$ & 0.999959753 & 0.59998 & 0.002556975 & 0.000010897 \\
4 & 0.011034979 & 0.000203915 & 0.999796085 & 0.59988 & 0.002556556 & 0.000010896 \\
5 & 0.005526403 & $5.11437 \mathrm{E}-05$ & 0.999948856 & 0.59997 & 0.002556947 & 0.000010897 \\
6 & 0.027810287 & 0.001295143 & 0.998704857 & 3.49547 & 0.014896969 & 0.000063488 \\
7 & 0.010963671 & 0.000201288 & 0.999798712 & 0.59988 & 0.002556563 & 0.000010896 \\
8 & 0.00875311 & 0.000128301 & 0.999871699 & 3.49955 & 0.014914374 & 0.000063562 \\
9 & 0.014992597 & 0.00037641 & 0.99962359 & 3.49868 & 0.014910673 & 0.000063546 \\
10 & 0.003404977 & $1.94149 \mathrm{E}-05$ & 0.999980585 & 0.59999 & 0.002557028 & 0.000010898 \\
11 & 0.009198787 & 0.000141699 & 0.999858301 & 3.49950 & 0.014914174 & 0.000063561 \\
12 & 0.015438275 & 0.000399121 & 0.999600879 & 0.59976 & 0.002556057 & 0.000010893 \\
13 & 0.015313485 & 0.000392695 & 0.999607305 & 0.59976 & 0.002556074 & 0.000010893 \\
14 & 0.005615539 & $5.28068 \mathrm{E}-05$ & 0.999947193 & 0.59997 & 0.002556943 & 0.000010897 \\
15 & 0.005348132 & $4.78973 \mathrm{E}-05$ & 0.999952103 & 3.49983 & 0.014915573 & 0.000063567 \\
\hline
\end{tabular}

Table 6: Relative costs for lines $(€)$

\section{Conclusion}

This study is about reliability of power distribution network. The presented reliability framework includes interdisciplinary aspects of life cycle analysis, consumer satisfaction index and power interruptions. These measures are summarized in terms of investment, repair and maintenance costs in the presented framework. The case study conducted on modified IEEE-14 bus network for generation outage scenarios demonstrate the relation between investments, repairs and maintenance costs to maintain the reliability. Apart from that, the system operator has an incentive in form of reducing direct investment to with marginal repair or maintenance cost. It is evident from the case study that the outages has an adverse impact on the system reliability and therefore results in additional cost. However, the additional cost can be shared with timely maintenance and repairs to avoid an up-front investment. Therefore, in an investment decision for network expansion, reliability analysis of the power network becomes significantly important to make an optimal decision. In future works, investment models with network restructuring will be studied. Application of classification techniques to evaluate weights for each edge in another research avenue, given that there are both empirical and quantitative information is included in the reliability criterion.

\section{References}

[1] R. Billinton, R. Karki, IEEE Transactions on Power systems 14, 1172 (1999)

[2] A.M.L. da Silva, L.A.F. Manso, W.S. Sales, L.C. Resende, M.J. Aguiar, M.A. Matos, J.A.P. Lopes, V. Miranda, European Transactions on Electrical Power 17, 387 (2007)

[3] R. Karki, R. Billinton, A.K. Verma, Reliability Modeling and Analysis of Smart Power Systems (Springer, 2014)

[4] H. Farzin, M. Fotuhi-Firuzabad, M. Moeini-Aghtaie, IEEE Transactions on Power Systems 33, 2359 (2018)

[5] R.N. Allan et al., Reliability evaluation of power systems (Springer Science \& Business Media, 2013)

[6] R. Billinton, W. Li, in Reliability Assessment of Electric Power systems Using Monte Carlo Methods (Springer, 1994), pp. 9-31

[7] A. Volkanovski, M. Čepin, B. Mavko, Reliability Engineering \& System Safety 94, 1116 (2009)

[8] J. Pylvänäinen, P. Verho, J. Järvinen, S. Kunttu, J. Sarsama, Advanced failure rate and distribution network reliability modelling as part of network planning software, in Electricity Distribution, 2005. CIRED 2005. 18th International Conference and Exhibition on (IET, 2005), pp. 1-5

[9] P. Jarventausta, J. Partanen, S. Karkkainen (2008) 
[10] J. Pylvanainen, J. Jarvinen, P. Verho, Advanced reliability analysis for distribution network, in Electric Utility Deregulation, Restructuring and Power Technologies, 2004.(DRPT 2004). Proceedings of the 2004 IEEE International Conference on (IEEE, 2004), Vol. 2, pp. 457-462

[11] W. He, X. Shen, J. Guo, Q. Wang, Y. Lu, H. Li, An improved design of damped AC test system for partial discharge measurement in distribution power cables, in IOP Conference Series: Materials Science and Engineering (IOP Publishing, 2018), Vol. 366, p. 012029
[12] A. Cataliotti, A. Daidone, G. Tinè, IEEE Transactions on Power Delivery 23, 1896 (2008)

[13] E. Cables, https://www.elandcables.com/electricalcable-and-accessories/cables-by-type/mediumvoltage-cable (2018)

[14] A. Cables, XLPE Land Cable Systems (2018)

[15] N. Ekstedt, P. Hilber, Categorization and review of failure rate factors used in power systems, in Probabilistic Methods Applied to Power Systems (PMAPS), 2014 International Conference on (IEEE, 2014), pp. $1-6$ 